\title{
Sistem Pendukung Keputusan Dalam Memetakan Wilayah Risiko Banjir Menggunakan Fuzzy Multi Criteria Decision Making
}

\author{
${ }^{1}$ Glorya Marseli Ontah, ${ }^{2}$ Winsy Ch. D. Weku, ${ }^{3}$ Altien J. Rindengan \\ ${ }^{1}$ Program StudiMatematika, F-MIPA, UNSRAT,ontahgloria@ yahoo.com \\ ${ }^{2}$ Program StudiMatematika, F-MIPA, UNSRAT, wins yweku@gmail.com \\ ${ }^{3}$ Program StudiMate matika, F-MIPA, UNSRAT,altien@uns rat.ac.id
}

\begin{abstract}
Abstrak
Banjir yang melanda di berbagai wilayah Indonesia merupakan suatu fenomena logis karena negara ini berada di daerah tropis dengan intensitas curah hujan yang sangat tinggi. Penelitian bertujuan untuk memetakan daerah berisiko banjir di Kota Manado. Pemetaan wilayah berisiko banjir di Kota Manado memerlukan beberapa pendapat atau masukan dari berbagai pihak. Atribut yang digunakan yaitu kemiringan lahan (\%), ketinggian wilayah (\%), DAS (km), luas pemukiman/wilayah tutupan lahan (\%) dan curah hujan (mm). Penentuan wilayah banjir di Kota Manado menggunakan Fuzzy Multi Criteria Decision Making (MCDM) dengan dua (2) metode yaitu Simple Additive Weighting Method (SAW) dan Technique for Order Preference by Similarity to Ideal Solution (TOPSIS). Hasil dengan menggunakan metode SAW dan SAW Fuzzy menunjukkan bahwa wilayah paling berisiko banjir yaitu Kecamatan Wenang. Hasil dengan menggunakan metode TOPSIS dan TOPSIS Fuzzy menunjukkan bahwa wilayah paling berisiko banjir yaitu Kecamatan Bunaken. Wenang sebagai wilayah banjir disebabkan lahan yang berada di dataran landai, ketinggian wilayah di bawah 240 meter, memiliki aliran sungai, intensitas curah hujan tinggi, dan besarnya tutupan lahan mencapai 94,59\%. Bunaken menjadi wilayah banjir karena Bunaken memiliki aliran sungai terpanjang di Kota Manado yaitu 17,9 km.
\end{abstract}

Kata kunci: Fuzzy, Kota Manado, MCDM, SAW, TOPSIS, Wilayah Banjir.

\section{Decision Support Systems in Flood Risk Mapping the Region Using Fuzzy Multi Criteria Decision Making (MCDM)}

\begin{abstract}
The floods that hit in various parts on Indonesia is a logical phenomenon because this country in the tropics with rainfall intensity is very high. Purpose of this research is to mapping flood risk areas in Manado. Mapping of flood risk in Manado need some opinions or input from various parties. Attributes used are slope $(\%)$, height of the region (\%), watershed (Miles), land cover $(\%)$ and rainfall $(\mathrm{mm})$. Determination of flood areas in Manado using Fuzzy Multi-Criteria Decision Making (MCDM) with two (2) methods : Simple Additive Weighting Method (SAW) and Technique for Order Preference by Similarity to ideal Solution (TOPSIS). Results using SAW and SAW Fuzzy methods showed that the area most at risk of flooding the district Wenang and results using TOPSIS and TOPSIS Fuzzy methods showed that the area most at risk of flooding the district Bunaken. Wenang as flooded areas because land is gently sloping terrain, altitude region below 240 meters, has a river flor, higher rainfall intensity, and magnitude of land cover reaches $94,59 \%$. Bunaken into flooded areas because it has the longest stream in Manado city is $17,9 \mathrm{~km}$.
\end{abstract}

Keywords : Fuzzy, Manado City, MCDM, SAW, TOPSIS, Flooded Areas.

\section{Pendahuluan}

Bencana alam merupakan proses alam yang dapat membahayakan kehidupan manusia sehingga harus dihindari, agar kehilangan jiwa dan harta dapat diminimalkan. Selain bencana yang dipicu oleh aktifitas alam, terdapat pula jenis bencana yang dipicu oleh aktifitas manusia sendiri. Indonesia merupakan negeri yang sangat rawan akan berbagai bencana alam, seperti kekeringan, banjir, tanah longsor, letusan gunung berapi, dan bencana gempa bumi serta tsunami. Banjir yang melanda di berbagai wilayah Indonesia merupakan suatu fenomena logis karena negara ini berada di daerah tropis dengan curah hujan yang sangat besar. Banjir merupakan bencana terbesar yang menempati urutan pertama. Berbagai pemicu dapat mengakibatkan banjir seperti perubahan lahan di daerah hulu dengan pembukaan hutan yang menyebabkan air hujan tidak dapat diserap oleh tanah sehingga menjadi air limpasan yang langsung mengalir ke sungai 
serta perkembangan wilayah perkotaan yang tidak diiringi dengan pengelolaan yang baik akan menyebabkan system drainase perkotaan akan memburuk sehingga air tidak mengalir dengan semestinya sehingga menyebabkan genangan air.

Fenomena-fenomena ini terjadi di wilayah Sulawesi Utara khususnya di beberapa kecamatan kota Manado yang pada beberapa waktu yang lalu mengalami bencana Banjir. Permasalahan banjir di kota manado selain disebabkan oleh curah hujan yang tinggi juga disebabkan beberapa faktor lainnya seperti kemiringan lahan, ketinggiaan wilayah (dpl), penutupan lahan, sistem drainase yang kurang baik, sampah masyarakat, serta banyaknya jumlah aliran air yang masuk ke kota manado sangat besar sehingga akumulasi aliran air sangat tinggi.

Lewat peristiwa banjir pada beberapa waktu yang lalu, dibutuhkan suatu pemahaman yang dapat dijadikan masukan bagi pemerintah daerah untuk lebih memberikan perhatian khusus wilayah mana saja yang berisiko banjir. Adapun maksud dari penelitian ini yaitu menentukan wilayah berisiko banjir di kota Manado serta memvisualisasikannya ke dalam bentuk peta tematik.

Pemetaan wilayah banjir merupakan suatu masalah keputusan spasial multikriteria yang memerlukan kemampuan informasi geografi. Dalam penelitian ini menggunakan pendekatan Fuzzy Multi Criteria Decision Making dalam memfasilitasi Spasial Decision Support System untuk menentukan wilayah banjir di kota Manado berdasarkan kriteria - kriteria penyebab banjir. Terdapat 2 metode yang akan digunakan yaitu Simple Additive Weighting (SAW) dan Technique for Order Preference by Similarity to the Ideal Solution (TOPSIS).

\section{Sis tem Pendukung Ke putus an}

Sistem pendukung keputusan pertama kali diperkenalkan pada tahun 1970 oleh Michael S. Scott dengan istilah management decision system yang merupakan suatu sistem berbasis komputer yang membantu pengambilan keputusan dengan memanfaatkan data dan model-model untuk menyelesaikan masalah-masalah yang tidak terstruktur. Sistem pendukung keputusan adalah sebuah sistem berbasis komputer yang dapat melakukan bantuan dalam pengambilan keputusan untuk memecahkan suatu masalah dengan memanfaatkan data dan model tertentu [5].

\section{Multi Criteria Decision Making (MCDM)}

Multi Criteria Decision Making (MCDM) adalah salah satu metode yang membantu dalam melakukan pengambilan keputusan terhadap beberapa alternatif keputusan yang harus diambil dengan beberapa kriteria yang akan menjadi bahan pertimbangan. Satu hal yang menjadi permasalahan adalah apabila bobot kepentingan dari setiap kriteria dan derajat kecocokan setiap alternatif terhadap setiap kriteria mengandung ketidakpastian [4].

Masalah MCDM dapat diklasifikasikan menjadi dua model (Zimmermann, 1991) yaitu Multi Attribute Decision Making (MADM) dan Multi Objective Decision Making (MODM). Pada MADM biasanya digunakan untuk me lakukan penilaian atau seleksi terhadap beberapa alternatif dalam jumlah yang terbatas. Sedangkan MODM digunakan untuk menyelesaikan masalahmasalah pada ruang kontinu (seperti permasalahan pada pemrograman matematisAda beberapa fitur umum yang akan digunakan dalam MCDM [3].

1. Alternatif

2. Atribut/kriteria

3. Konflik antar kriteria

4. Bobot keputusan

5. Matriks keputusan

SAW

Metode SAW sering juga dikenal dengan istilah metode penjumlahan terbobot. Konsep dasar metode SAW adalah mencari penjumlahan terbobot dari rating kinerja pada setiap alternatif pada semua atribut. Metode SAW membutuhkan proses normalisasi matriks keputusan (X) ke suatu skala yang dapat diperbandingkan dengan semua rating alternatif yang ada. Total skor untuk setiap alternatif dihitung dengan mengalikan tingkat pembanding untuk masing-masing atribut dengan kepentingan bobot yang diberikan terhadap atribut dan kemudian menjumlahakan perkaliannya terhadap semua atribut[1]. 


$$
r_{i j}= \begin{cases}\frac{x_{i j}}{\max x_{i j}} & ; j i k a j \text { adalah atribut keuntungan (Benefit) } \\ \frac{\mathrm{i}}{\min x_{i j}} & \text { jikaj adalah atribut biaya (cost) }\end{cases}
$$

Dimana $\mathrm{r}_{\mathrm{ij}}$ adalah rating kinerja ternorma lisasi dari alternatif $A_{i}$ pada atribut $C_{j}$ dimana $i=1,2, \ldots, m$ dan $j=1,2, \ldots ., n$. Nilai preferensi untuk setiap alternatif $\left(V_{i}\right)$ diberikan sebagai :

$$
V i=\sum_{j=1}^{n}\left(w_{j} r_{i j}\right)
$$

Nilai $V_{i}$ yang lebih besar mengindikasikan bahwa alternatif $A_{i}$ lebih terpilih.

\section{Technique for Order Performance by Similarity to Ideal Solution (TOPSIS)}

TOPSIS adalah salah satu metode pengambilan keputusan multikriteria yang pertama kali diperkenalkan oleh Yoon dan Hwang (1981). TOPSIS menggunakan prinsip bahwa alternatif yang terpilih harus mempunyai jarak terdekat dari solusi ideal pos itif dan jarak terpanjang (terjauh) dari solusi ideal negatif. Solusi ideal positif didefinisikan sebagai jumlah dari seluruh nilai terbaik yang dapat dicapai untuk setiap atribut, sedangkan solusi negatif-ideal terdiri dari seluruh nilai terburuk yang dicapai untuk setiap atribut. Teknik TOPSIS didef inis ikan sebagai suatu 'kesamaan indeks'(kedekatan relatif) dengan menggabungkan kedekatan terhadap penyelesaian ideal positif dan jarak terjauh dari penye lesaian ideal negatif [1].

Adapun langkah-langkah algoritma dari TOPSIS ini adalah sebagai berikut :

1. Rangking Tiap Alternatif

TOPSIS membutuhkan ranking kinerja setiap alternatif $(A i)$ pada setiap kriteria $(C j)$ yang ternormalisasi yaitu :

$$
\boldsymbol{r}_{i j}=\frac{x_{i j}}{\sqrt{\sum_{t=1}^{m} x_{i j}^{2}}} \quad \text { dengan } i=1,2, \ldots m \text { dan } j=1,2, \ldots n
$$

2. Matriks keputusan ternormalisasi terbobot

$$
\mathrm{y}_{\mathrm{ij}}=\mathrm{w}_{\mathrm{i}} \mathrm{r}_{\mathrm{ij}} \mathrm{p} \text {, dengan } i=1,2, \ldots m \text { dan } j=1,2, \ldots n
$$

3. Solusi Ideal Positif Dan Negatif

Solusi ideal positif $A+$ dan solusi ideal negatif $A$ - dapat ditentukan berdasarkan ranking bobot ternormalisasi $\left(y_{i j}\right)$ sebagai berikut :

$$
\begin{aligned}
& A^{+}=\left(y_{1}^{+}, y_{2}^{+}, \ldots, y_{n}^{+}\right) \\
& A^{-}=\left(y_{1}^{-}, y_{2}^{-}, \ldots . ., y_{n}^{-}\right) \\
& \text {dimana } y_{j}^{+} \text {adalah } \quad-\max y_{i j} \text { jika j adalah atribut keuntungan } \\
& \text { - } \quad \min y_{i j} \text { jika } \mathrm{j} \text { adalah atribut biaya } \\
& y_{j}^{-} \text {adalah } \quad-\min y_{i j} \text { jika } \mathrm{j} \text { adalah atribut keuntungan } \\
& \text { - } \quad \max y_{i j} \text { jika } \mathrm{j} \text { adalah atribut biaya }
\end{aligned}
$$

4. Jarak Dengan Solusi Ideal

Jarak dengan alternatif $A_{i}$, dengan solusi ideal positif dirumuskan sebagai:

$D_{i}^{+}=\sqrt{\sum_{j=1}^{n}\left(x_{i}^{+}-y_{i}^{-}\right)^{2}} ; i=1,2, \ldots m$

Jarak adalah alternatif $\mathrm{A}_{\mathrm{i}}$ dengan solusi ideal negatif dirumuskan sebagai :

$D_{i}^{-}=\sqrt{\sum_{j=1}^{n}\left(y_{1}^{+}-y_{i j}^{-}\right)^{2}} ; i=1,2, \ldots m$

5. Nilai Preferensi Untuk Setiap Alternatif

Nilai preferensi untuk setiap alternatif (Vi) diberikan sebagai :

$V_{i}=\frac{D_{i}^{-}}{D_{i}^{-}+D_{i}^{+}} ; I=1,2, \ldots m$

Nilai $V_{i}$ yang lebih besar menunjukkan bahwa alternatif $A_{i}$ lebih dipilih. 
Fuzzy

Logika fuzzy merupakan peningkatan dari logika Boolean yang diperkenalkan oleh Dr. Lotfih Zadeh dari Universitas California, Berkeley pada tahun 1965. Dalam logika Boolean menyatakan bahwa segala sesuatu hanya dapat diekspresikan dalam dua nilai yaitu 0 dan 1 , hitam dan putih, ya atau tidak. Dalam logika fuzzy memungkinkan nilai keanggotaan antara 0 dan 1 , sehingga dalam logika fuzzy mengenal istilah hitam, keabuan, dan putih atau sedikit, lumayan dan sangat [2].

Beberapa hal yang perlu diketahui da lam memahami sistem fuzzy, yaitu :

1. Variabel fuzzy yang merupakan variabel yang hendak dibahas dalam suatu Sistem fuzzy.

2. Himpunan fuzzy yang merupakan suatu grup yang mewakili suatu kondisi atau keadaan tertentu dalam suatu variabel fuzzy.

3. Semesta Pembicaraan adalah keseluruhan nilai yang diperbolehkan untuk dioperasikan dalam suatu variabel fuzzy.

4. Domain himpunan fuzzy adalah keseluruhan nilai yang diijinkan dalam semesta pembicaraan dan boleh dioperasikan dalam suatu himpunan fuzzy. Fungsi keanggotaan (membership function) adalah suatu kurva yang menunjukkan pemetaan titik-titik input data ke dalam nilai keanggotaannya (sering juga disebut dengan derajat keanggotaan) yang memiliki interval antara 0 sampai 1[6].

\section{Metodologi Penelitian}

Data penelitian yang digunakan yaitu data sekunder berupa data curah hujan, kemiringan lahan, ketinggian tempat, tutupan lahan, dan DAS. Data Kemiringan lahan, ketinggian wilayah, dan DAS diambil dari Badan Pusat Statistik Provinsi Sulawesi Utara. Data Tutupan lahan diambil dari Jurnal Info BPK Manado Volume 2 No 1 dan data curah hujan diambil dari BMKG Kayuwatu Manado.

Kriteria-kriteria yang menentukan wilayah banjir di kota Manado disajikan dalam Tabel 1.

Tabel 1. Kriteria dan Indikator Penentuan Wilayah Banjir

\begin{tabular}{|c|c|}
\hline Kriteria & Indikator \\
\hline Kemiringan & Wilayah berpotensi banjir pada ke miringan 0-8 \% \\
\hline Ketinggian & Wilayah berpotensi banjir pada ketinggian 0-240 m dpl \\
\hline DAS & $\begin{array}{c}\text { Semakin panjang aliran sungai semakin berpotensi } \\
\text { untuk terjadi banjir }\end{array}$ \\
\hline $\begin{array}{c}\text { Tutupan } \\
\text { Lahan }\end{array}$ & $\begin{array}{c}\text { Semakin luas daerah pemukiman maka semakin } \\
\text { berpotensi terjadi banjir }\end{array}$ \\
\hline Curah Hujan & Semakin tinggi semakin berpotensi banjir \\
\hline
\end{tabular}

Berdasarkan Tabel 1 dilakukan survey terhadap 9 kecamatan di kota Manado. Nilai indikator dari setiap kriteria per kecamatan disajikan dalam Tabel 2.

\section{Hasil dan Pembahasan}

Tabel 2. Nilai dari setiap kriteria per kecamatan

\begin{tabular}{|l|c|c|c|c|c|}
\hline \multirow{2}{*}{ Wilayah } & \multicolumn{5}{|c|}{ Kriteria } \\
\cline { 2 - 6 } & $\begin{array}{c}\text { Kemiringan } \\
(\%)\end{array}$ & $\begin{array}{c}\text { Ketinggian } \\
(\%)\end{array}$ & $\begin{array}{c}\text { DAS } \\
(\mathrm{km})\end{array}$ & $\begin{array}{c}\text { Tutupan Lahan } \\
(\%)\end{array}$ & $\begin{array}{c}\text { Curah Hujan } \\
(\mathrm{mm})\end{array}$ \\
\hline Bunaken & 6 & 74.01 & 17.9 & 8.18 & 385 \\
\hline Sario & 100 & 100 & 3 & 97.51 & 345 \\
\hline Tuminting & 90 & 100 & 0 & 75.85 & 229 \\
\hline Singkil & 89 & 100 & 5 & 51.50 & 531 \\
\hline Wanea & 25 & 100 & 3.72 & 63.63 & 345 \\
\hline Malalayang & 29 & 100 & 4.80 & 37.06 & 345 \\
\hline Mapanget & 65 & 98.69 & 0 & 12.87 & 426 \\
\hline Wenang & 100 & 100 & 6 & 94.59 & 531 \\
\hline Tikala & 16 & 100 & 7.56 & 32.14 & 452 \\
\hline
\end{tabular}


Setelah mendapatkan tabel 2, dilanjutkan dengan MCDM yaitu SAW dan TOPSIS. Dalam MCDM ada beberapa hal yang harus diperhatikan yaitu normalisasi matriks dan pembobotan kriteria. Proses normalisasi dalam SAW disebut dengan normalisasi skor maksimum dan dalam TOPSIS disebut dengan normalisasi vektor. Pembobotan kriteria dilakukan berdasarkan tingkat kepentingan tiap kriteria, semakin penting kriteria tersebut maka semakin tinggi bobot kriteria, dalam hal bobot kriteria yang diberikan yaitu 1- 5. Dalam penelitian ini kriteria curah hujan berbobot 5, kriteria DAS berbobot 4, kriteria tutupan lahan berbobot 3 dan kriteria kemiringan dan juga ketinggian berbobot 2. Setelah melakukan teknik MCDM maupun FMCDM, akan diketahui wilayah mana yang merupakan wilayah yang paling berpotensi banjir.

Hasil perhitungan metode SAW dan Fuzzy SAW disajikan dalam Tabel 3.

Tabel 3. Hasil Perhitungan Metode SAW dan Fuzzy SAW

\begin{tabular}{|l|c|c|c|c|}
\hline \multirow{2}{*}{ Kecamatan } & \multicolumn{2}{|c|}{ SAW } & \multicolumn{2}{c|}{ Fuzzy SAW } \\
\cline { 2 - 5 } & Nilai & Peringkat & 2,3376 & Pilai \\
\hline Bunaken & 0,5923 & 4 & 2,7500 & 3 \\
\hline Sario & 0,6824 & 3 & 2,4500 & 4 \\
\hline Tuminting & 0,5181 & 7 & 3,0075 & 2 \\
\hline Singkil & 0,7176 & 2 & 2,1875 & 8 \\
\hline Wanea & 0,5336 & 6 & 2,2700 & 6 \\
\hline Malalayang & 0,5026 & 8 & 2,0059 & 9 \\
\hline Mapanget & 0,4801 & 9 & 3,2500 & 1 \\
\hline Wenang & 0,8282 & 1 & 2,2050 & 7 \\
\hline Tikala & 0,5784 & 5 & & \\
\hline
\end{tabular}

Visualisasi dari hasil perhitungan matlab ke bentuk peta tematik disajikan dalam Gambar 1.

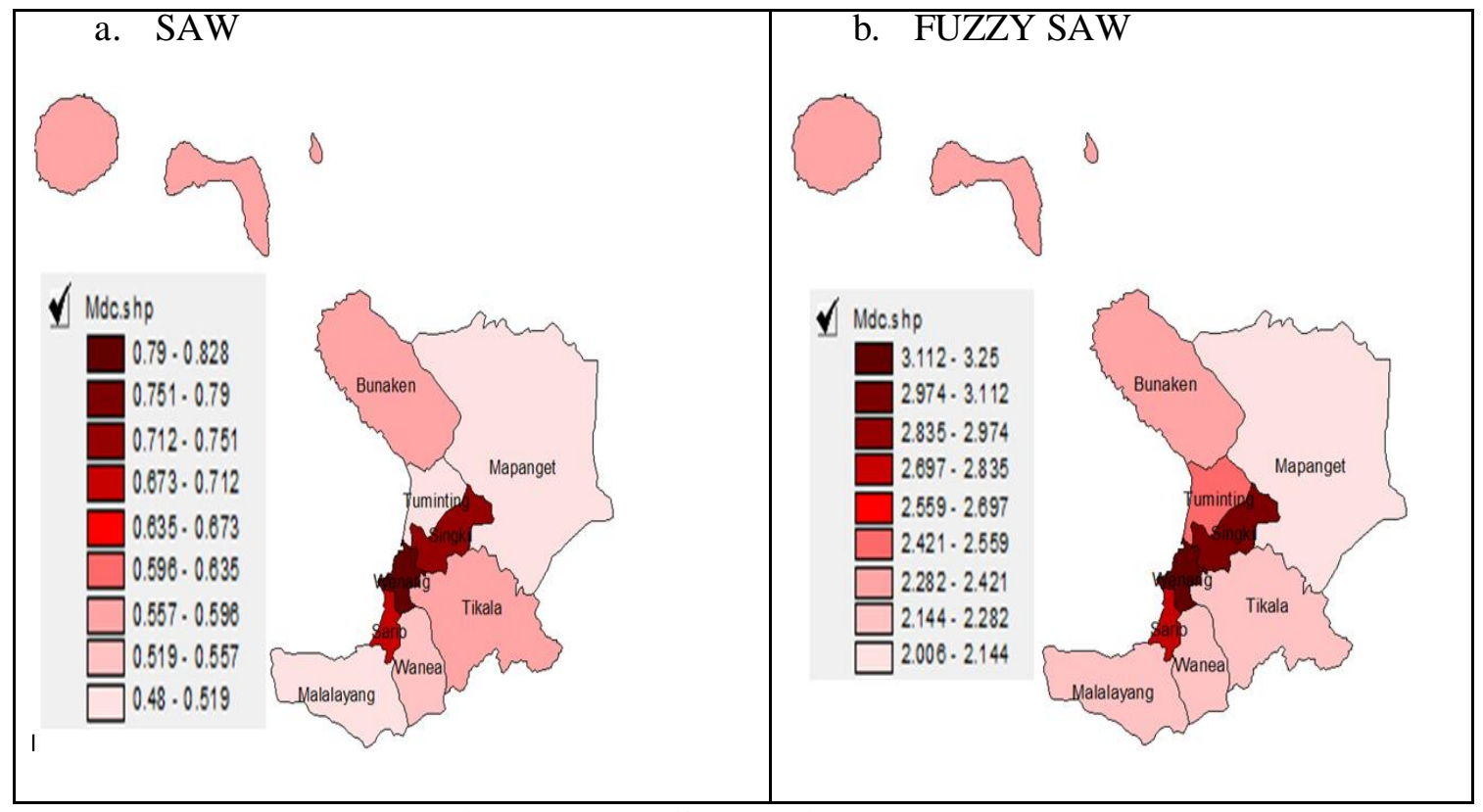

Gambar 1. Peta Banjir SAW dan Fuzzy SAW

Tabel 4 dan Gambar 1 menunjukan hasil perhitungan metode SAW dan Fuzzy SAW. Peta Banjir menurut metode SAW dengan data non-fuzzy menunjukan kecamatan Wenang adalah kecamatan dengan potensi banjir tertinggi selanjutnya diikuti oleh kecamatan Singkil dan kecamatan Sario kemudian kecamatan Bunaken, Tikala, Wanea, Tuminting, Malalayang dan Mapanget secara berturut-turut berada pada urutan 4, 5, 6, 7, 8 dan 9.

Peta banjir menurut SAW fuzzy menunjukan kecamatan Wenang menjadi wilayah dengan potensi banjir tertinggi selanjutnya kecamatan Singkil, Sario, Tuminting, Bunaken, Malalayang, Tikala, Wanea dan Mapanget secara berturut-turut berada pada urutan 2, 3, 4, 5, 6, 7, 8, dan 9 .

Kecamatan Wenang menjadi wilayah paling berpotensi banjir di Manado dikarenakan Wenang mendominasi semua kriteria penyebab banjir. Luas wilayah Wenang berada pada 
kemiringan lahan $0-8 \%$ (dataran landai), Wenang berada pada ketinggian $0-240$ meter dpl, memiliki aliran sungai yang cukup panjang, intesitas curah hujan tertinggi dan besarnya tutupan lahan di kecamatan Wenang mencapai 94,59\% dari luas wilayahnya. Perhitungan SAW dan SAW fuzzy menunjukan juga kecamatan Mapanget merupakan wilayah dengan potensi banjir terendah di Kota Manado

Hasil perhitungan metode TOPSIS dan Fuzzy TOPSIS disajikan dalam Tabel 4.

Tabel 4. Hasil Perhitungan Metode TOPSIS bobot non-Fuzzy dan TOPSIS Bobot Fuzzy

\begin{tabular}{|c|c|c|c|c|}
\hline \multirow{2}{*}{ Kecamatan } & \multicolumn{2}{|c|}{ TOPSIS } & \multicolumn{2}{c|}{ TOPSIS FUZZY } \\
\cline { 2 - 5 } & Nilai & Peringkat & Nilai & Peringkat \\
\hline Bunaken & 0,6436 & 1 & 0,5842 & 1 \\
\hline Sario & 0,4007 & 5 & 0.4158 & 4 \\
\hline Tuminting & 0,2844 & 8 & 0,3797 & 5 \\
\hline Singkil & 0,4325 & 3 & 0,5243 & 3 \\
\hline Wanea & 0,3063 & 6 & 0,2782 & 8 \\
\hline Malalayang & 0,2904 & 7 & 0,3472 & 6 \\
\hline Mapanget & 0,2192 & 9 & 0,2406 & 9 \\
\hline Wenang & 0,5219 & 2 & 0,5688 & 2 \\
\hline Tikala & 0,4220 & 4 & 0,3343 & 7 \\
\hline
\end{tabular}

Berikut ini adalah visualisasi dari hasil perhitungan matlab ke bentuk peta tematik.

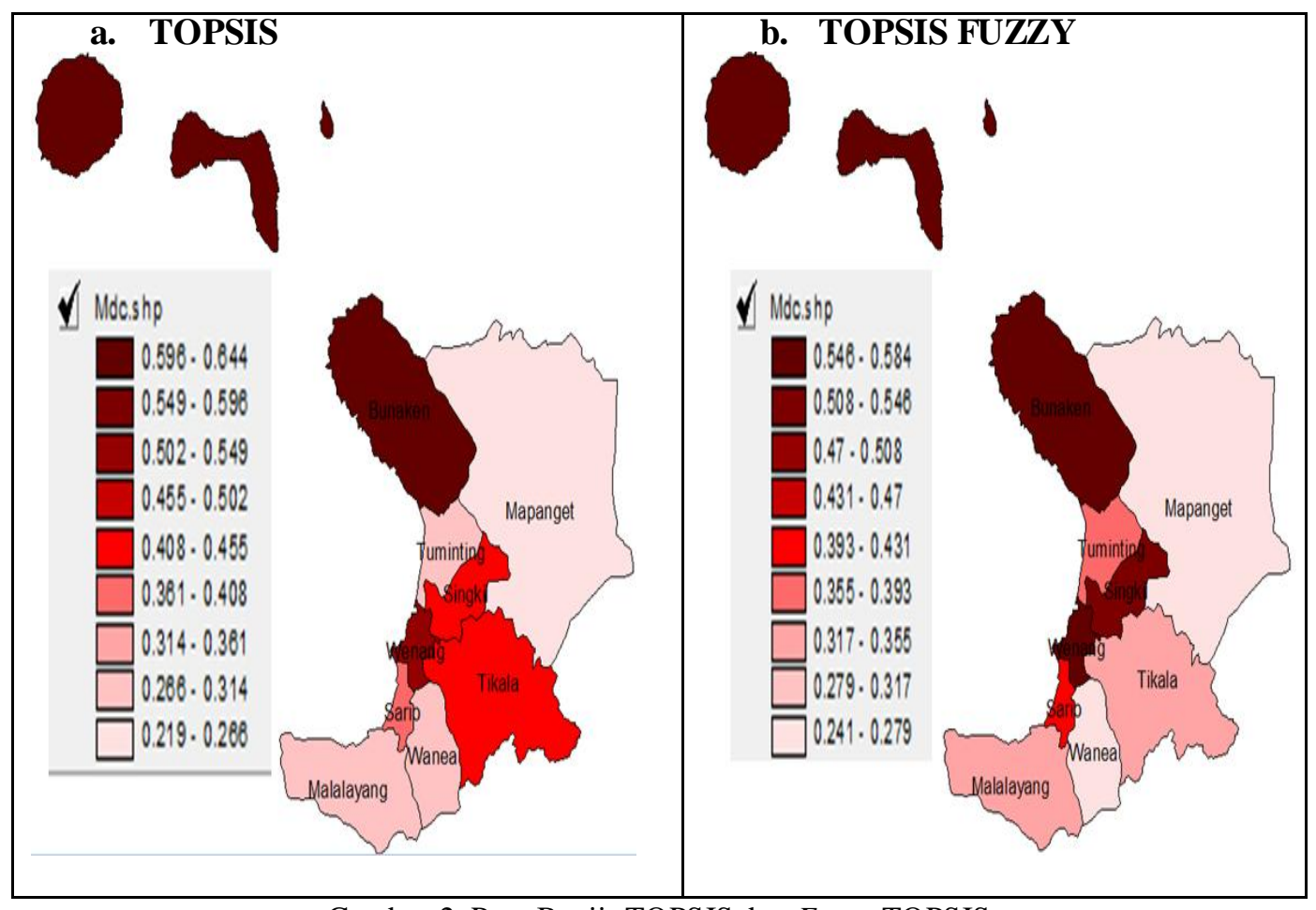

Gambar 2. Peta Banjir TOPSIS dan Fuzzy TOPSIS

Tabel 5 dan Gambar 2 menunjukan hasil perhitungan metode TOPSIS non-fuzzy dan TOPSIS fuzzy. Peta banjir menurut metode TOPSIS non-fuzzy kecamatan paling berisiko banjir adalah kecamatan Bunaken, diikuti oleh kecamatan Wenang dan kecamatan Singkil. Kecamatan Tikala, Sario, Wanea, Malalayang, Tuminting, dan Mapanget secara berturut-turut berada di urutan $4,5,6,7,8$, dan 9 . 
Peta banjir menurut TOPSIS fuzzy menunjukan hasil yang sama dengan metode TOPSIS non-Fuzzy yaitu Kecamatan Bunaken sebagai wilayah paling berpotensi banjir di kota Manado selanjutnya diikuti oleh kecamatan Wenang dan Singkil. Kecamatan Sario, Tuminting, Malalayang, Tikala, Wanea dam Mapanget secara berturut-turut berada pada urutan 4, 5, 6, 7, 8, dan 9.

Kecamatan Bunaken menjadi kecamatan paling berisiko banjir disebabkan Bunaken memiliki a liran sungai terpanjang di Kota Manado yaitu 17,9 km. Hasil perhitungan TOPSIS nonFuzzy dan TOPSIS Fuzzy menunjukan kecamatan Mapanget sebagai wilayah dengan potensi banjir terendah di kota manado.

\section{Kesimpulan}

Dalam penelitian ini dapat diambil kesimpulan bahwa :

1. Berdasarkan analis is Multikriteria dengan menggunakan metode SAW non-fuzzy maupun SAW Fuzzy, menunjukan kecamatan Wenang sebagai wilayah paling berpotensi banjir di kota Manado. Wenang sebagai wilayah banjir di Kota Manado ditunjang dengan kemiringan lahan yang berada di dataran landai, ketinggian wilayah berada di bawah 240 meter dpl, memiliki aliran sungai, intensitas curah hujan tertinggi dan besarnya tutupan lahan mencapai $94,59 \%$.

2. Metode TOPSIS non-fuzzy maupun TOPSIS Fuzzy menunjukan Kecamatan Bunaken yeng menjadi wilayah paling berpotensi banjir di kota Manado. Bunaken sebagai wilayah banjir karena Bunaken memiliki aliran sungai terpanjang di kota Manado yaitu 17,9 Km.

3. Kecamatan Mapanget merupakan kecamatan yang memiliki tingkat kerawanan banjir terendah di kota Manado berdasarkan metode SAW, SAW FUZZY, TOPSIS dan TOPSIS FUZZY.

\section{Daftar Pus taka}

[1] Azar, F.S. 2000. Multiattribute Desicion Making : Use of Three Scoring Methods to Compare The Perfomance of Imaging Techniques for Breast Cancer Detection. Penns ylvania, Philadelphia.

[2] Chen, Guanrong and Pham, Trung Tat. 2000. Introduction to Fuzzy Sets, Fuzzy Logic, and Fuzzy Control System. CRC Press, London.

[3] Janco, W. 2005. Multy-Criteria Decision Making: Aplikasi Studi pada ELECTRE dan TOPSIS dalam Fuzzy Multi-Atrtribute Decision Making (Fuzzy MADM). Graha Ilmu, Yogyakarta.

[4] Kusumadewi, S. dan I. Guswaludin. 2005. Fuzzy Multi-Criteria Decision Making (Fuzzy MCDM). Universitas Islam Indonesia, Yogyakarta.

[5] Turban, E. 2005. Decision Support System and Intelligent System (Sistem Pendukung Keputusan dan Sistem Cerdas). Andi, Yogyakarta.

[6] Yuan, B. and. Klir, George. 1995. Fuzzy Set and Fuzzy Logic : Theory And Aplications.Prentice Hall International, INC, New Jersey. 